\title{
MEMPERSIAPKAN CALON GURU MATEMATIKA DAN IPA DALAM MENGHADAPI ERA INDUSTRI 4.0
}

\author{
Erik Santoso $^{1}$, Muhamad Kurnia Sugandi ${ }^{2}$, Attin Warmi ${ }^{3}$, Alpha Galih Adirakasiwi ${ }^{4}$ \\ ${ }^{1,2}$ Fakultas Keguruan dan Ilmu Pendidikan, Universitas Majalengka, Jl. Raya K H Abdul Halim \\ No.103, Majalengka Kulon, Kec. Majalengka, Kabupaten Majalengka, Jawa Barat 4541 \\ ${ }^{3,4}$ Fakultas Keguruan dan Ilmu Pendidikan, Universitas Singaperbangsa Karawang, Jl. HS.Ronggo \\ Waluyo, Puseurjaya, Kec. Telukjambe Tim., Kabupaten Karawang, Jawa Barat 41361 \\ e-mail: *11eriksantoso@unma.ac.id, ${ }^{2}$ kurniasugandi@unma.ac.id, ${ }^{3}$ attinwarmi@unsika.ac.id \\ 3alphagalihadirakasiwi@unsika.ac.id
}

\begin{abstract}
ABSTRAK
Sumber Daya Manusia (SDM) yang berkualitas menjadi kunci untuk setiap Negara dapat menjadikan negaranya merupakan Negara yang maju dan bersaing dengan Negara lain. Pendidikan menjadi kunci dalam mepersiapkan SDM yang mampu bersaing di era insutri 4.0. Metode dalam penulisan artikel ini adalah kajian dari artikel yang berkaitan dengan kesiapan calon guru matematika dan IPA dalam menghadapi era industry 4.0. Melalui kajian ini dapat disimpulkan bahwa 3 hal yang harus dipersiapkan agar calon guru MIPA bisa bersaing di Era Industri 4.0 adalah guru yang memiliki karakter, guru yang mampu menciptakan lingkungan pembelajaran yang kaya serta guru yang mampu dan cakap terhadap penguasan teknologi.
\end{abstract}

Kata Kunci : Calon guru matematika, Calon guru IPA, Era Industri 4.0

\section{PENDAHULUAN}

Pembangunan Sumber Daya Manusia (SDM) merupakan kunci sukses Negara dalam mempersiapkan negaranya untuk dapat bersaing dengan Negara lain. Hal ini sesuai dengan pendapat keberhasilan pembangunan tercermin dalam sumber daya manusia yang berkualitas (Rahim et al., 2019). SDM yang berkualitas menjadi kunci untuk setiap Negara dapat menjadikan negaranya merupakan Negara yang maju dan bersaing dengan Negara lain. Oleh karena itu pendidikan menjadi kunci utama dalam mempersiapkan SDM yang berkualitas tersebut.

Sepanjang hayat, manusia tidak pernah terlepas dari yang namanya pendidikan (Hendayani, 2019). Mulai dari lahir sampai dengan meninggal manusia tidak pernah lepas dengan yang namnya pendidikan. Pendidikan memberikan proses perubahan tingkah laku dari yang kurang baik menjadi baik. Pendidikan pula yang dapat mempersiapkan seseorang untuk dapat bertahan dalam situasi persaingan yang sangat kencang sekarang ini. Oleh karena itu pendidikan yang berkualitas merupakan kunci utama dari semuanya.

Akar dari permasalahan ini adalah guru belum mempersiapkan diri dengan matang menghadapi perubahan zaman (Rahim et al., 2019). Zaman sekarang adalah zaman dimana menjadi teknologi bukanlah sebagai gaya hidup melainkan teknologi menjadi kebutuhan yang sangat penting dalam era dimana semua terkoneksi dengan internet. 
Dulu kita belum membayangkan bagaimana tol yang ada di Indonesia bisa terintegrasi sehingga petugas tol sudah tidak lagi membutuhkan tenaga manusia, inilah disebut dengan era dimana sebagian pekerjaan manusia akan tergantikan dengan teknologi dan robot. Era ini disebut dengan era revolusi industri 4.0

Perubahan di era revolusi 4.0 ini pun berkembang sangat cepat (Wati \& Kamila, 2019). Senada dengan hal tersebut Era revolusi industri 4.0 mengubah konsep pekerjaan, struktur pekerjaan, dan kompetensi yang dibutuhkan dunia pekerjaan. Fokus pada transformasi bisnis ke platform digital telah memicu permintaan profesional Sumber Daya Manusia (SDM) yang memiliki kompetensi yang jauh berbeda dari sebelumnya (Surani, 2019).

Era Industri 4.0 memungkinkan semua orang dapat terhubung tanpa mengenal batas tempat dan waktu. Ini terjadi ketika dunia di landa Pandemi Global Covid-19 semua pembelajaran melakukan akses internet dengan berbagai platform yang tersedia. Perlu kesiapan karena ini memberikan peluang agar kita siap dalam menyiapkan SDM yang berkualitas tadi. Apalagi Indonesia sendiri akan masuk 100 tahun kemerdekaan yang disebut dengan generasi emas.

Perkembangan global abad ke-21 telah demikian kompleks. Suatu bangsa akan eksis dan maju manakala mampu menjawab tantangan global dengan baik. Disini, kata kuncinya adalah pendidikan yang baik. Dengan pendidikan yang baik, kita mempersiapkan sumber daya manusia terdidik, dengan kompetensi yang dapat diandalkan mengangkat derajat daya saing bangsa: menjadi bangsa yang maju dan kompetitif.Untuk bisa memanfaatkan bonus demograsi menjadi asset nasional, maka kunci strategisnya adalah masalah pendidikan (Karima \& Ramadhani, 2017).

Indonesia akan menuju kebangkitan kedua, yaitu 100 tahun Indonesia merdeka pada tahun 2045. Inilah yang melatarbelakangi kebangkitan generasi emas. Inilah saat yang tepat bagi pendidikan untuk berperan menciptakan generasi emas Indonesia. Ini adalah momentum sangat tepat bagi para pemangku kepentingan pendidikan untuk menata dengan sebaik-baiknya pendidikan berkualitas (Darman, 2017).

Pembelajaran yang berkulitas ditandai oleh pencapaian tujuan yang telah ditetapkan dengan maksimal. Kualitas pembelajaran sangat bergantung dari berbagai faktor, salah satu faktor penting adalah faktor guru sebagai orang yang terlibat langsung dalam proses pembelajaran sehari-hari. Guru yang profesional tentu bisa melaksanakan pembelajaran dengan baik (Susongko et al., 2020) (Amini et al., 2020) (Subekt et al., 2017).

Pendidikan dalam mempersiapkan generasi 2045 sangat penting. Itulah sebabnya, Lembaga Pendidikan dan Tenaga Kependidikan (LPTK) perlu menyiapkan pendidikan tenaga pendidik untuk menyiapkan generasi 2045 itu, dan manajemen ketenagaan pendidik yang profesional. Dalam konteks penyiapan generasi 2045, peran pendidik sangatlah penting dan masa depan bangsa ada di pundak pendidik atau guru (Khairat, 2016) (Arifian, 2019).

Era persaingan ini dihadapkan bagaimana calon guru matematika dan IPA (MIPA) memiliki kompetensi yang baik dan juga memiliki karakter dan kecakapan terhadap teknologi internet. Guru MIPA menjadi terdepan karena memiliki peranan yang sangat penting dalam perkembangan teknologi, matematika memiliki peranna kunci dalam perkembangan teknologi dan IPA memberikan peran untuk mengenal antara Tuhan dan ciptan-Nya. Melalu kajian ini dapat memberikan kajian yang komperhensif bagaimana calon guru MIPA dalam menghadapi persaingan yang sangat ketat ini.

\section{METODE}

Artikel ini merupakan pendalaman terhadap artikel yang berkaitan dengan karakter guru dalam menghadapi era 
Industri 4.0, juga bagaimana kesiapan LPTK dalam menyiapkan calon guru matematika dan IPA yang mampu bersaing dalam dunia yang sarat dengan persaingan.

\section{HASIL DAN PEMBAHASAN \\ 1. Calon Guru Matematika dan IPA yang Berkarakter}

Generasi emas adalah generasi yang mempunyai keterampilan abad 21 (Mahanal, 2014). Generasi emas adalah generasi yang memiliki karakter sesuai dengan filsafah bangsanya, Falsafah bangsa Indonesia salah satunya adalah gotong royong.

Tantangan yang lebih besar pada saat ini adalah krisis sumber daya manusia terutama dalam krisis karakter (Abi, 2017). Mempersiapkan siswa dalam menyongsong generasi emas dapat dilakukan dengan berbagai cara, salah satunya dengan membangun karakter (Ferryka, 2013). Karakter menjadi penting karena dengan karakter yang kuat seseorang tidak akan terpengaruhi oleh budaya lain yang tidak sesuai dengan falsafah dan pandangan hidup bangsa Indonesia.

Secara harfiah, karakter berasal dari bahasa inggris, character yang berarti watak, karakter, atau sifat (Khairat, 2016). Sementara itu Imam al-Ghazali mendefinisikan karakter sebagai akhlak, yakni spontanitas seorang manusia dalam bertutur kata dan bersikap, atau melakukan perbuatan yang telah menyatu dalam dirinya sehingga ketika muncul tidak perlu dipikirkan lagi (Hendayani, 2019). Karakter berdasarkan dua pendapat tersebut adalah sikap yang sudah tertanam dalam diri manusia sehingga dia tidak terpengaruh banyak oleh orang lain.

Kemendikbud membuat desain pendidikan karakter dengan membuat daftar sifat-sifat yang harus diimplementasikan kepada peserta didik. Diantaranya daftar sifat tersebut adalah sifat religius, jujur, toleransi, disiplin, kerja keras, kreatif, demokratis, cinta tanah air, menghargai perestasi, gemar membaca, tanggung jawab, peduli sosial serta peduli terhadap lingkungan sekitar (Khairat, 2016). Disiplin, jujur dan kreatif menjadi kunci dalam kesuksesan seseorang. Seorang calon guru yang akan menghadapi siswa nanti dituntut untuk memiliki sikap kreatif dimana dia bisa melakukan inovasi dalam pembelajaran, pembelajaran yang dilaksanakan menjadi lebih dinamis dan menjadi lebih menyenangkan.

Menurut Lickona (Sudrajat, 2011) ada tujuh alasan mengapa pendidikan karakter itu harus disampaikan. Ketujuh alasan yang dimaksud adalah sebagai berikut.

a. Cara terbaik untuk menjamin anakanak (siswa) memiliki kepribadian yang baik dalam kehidupannya.

b. Cara untuk meningkatkan prestasi akademik.

c. Sebagian siswa tidak dapat membentuk karakter yang kuat bagi dirinya di tempat lain

d. Persiapan siswa untuk menghormati pihak atau orang lain dan dapat hidup dalam masyarakat yang beragam.

e. Berangkat dari akar masalah yang berkaitan dengan problem moralsosial, seperti ketidaksopanan, ketidakjujuran, kekerasan, pelanggaran kegiatan

f. seksual, dan etos kerja (belajar) yang rendah.

g. Persiapan terbaik untuk menyongsong perilaku di tempat kerja.

h. Pembelajaran ni lai-ni lai budaya yang merupakan bagian dari kerja peradaban.

Betapa pentingnya karakter yang harus dimiliki oleh guru MIPA maka guru MIPA harus memiliki kemampuan inovasi yang baik agar siswa bisa belajar dengan baik, karena dua mata pelajaran ini biasanya memiliki banyak permasalahan salahsatunya proses pembelajaran yang hanya berjalan satu arah, oleh karena itu kreatif menjadi kuncinya. 


\section{Calon Guru Matematika dan IPA yang Mampu Menciptakan Lingkungan Pembelajaran yang Kaya}

Guru profesional dan berwibawa tidak dapat dihasilkan dengan instan (Rohmadi, 2016). Betul bahwa proses pembentukan guru professional melewati beberapa tahap dan harus dilewati panjang. Guru harus mampu meningkatkan keempat kompetensi yang dimilikinya.. Guru MIPA dituntut untuk mampu menciptakan kaya yang bisa disebut dengan pembelajaran yang menyenangkan bagi siswanya.

Pembelajaran sains menghendaki siswa untuk terlibat langsung secara aktif yang terimplikasikan dalam kegiatan secara fisik ataupun mental (Yuliati \& Saputra, 2019). Kemudian di perkuat oleh pendapat Pembelajaran menyenangkan adalah pembelajaran dimana interaksi antara pengajar dan siswa, lingkungan fisik, dan suasana memberikan peluang terciptanya kondisi yang kondusif untuk belajar. Suasana (Susongko et al., 2020).

Salah satu ciri yang dapat terlihat dari pembelajaran yang kaya adalah adalah adanya proses bertukar informasi melalu kegiatan diskusi yang terjadi dua arah antara siswa dengan siswa dan guru hanya berperan sebagai fasilitator. Lingkungan pembelajaran yang kaya dapat tercerminkan jika kemampuan berpikir tingkat tinggi siswa mampu muncul di dalam pembelajaran, kuncinya siswa harus membiasakan diri dengan kemampuan berpikir kritis dan kreatis. Kritis akan memunculkan dan melahirkan kemampuan berpikir kreatif. Orang yang berpikir kritis tentu akan memiliki altertanif dalam menyelesaikan masalah dan orang kreatif akan memilih jalan mana yang terbaik untuk bisa memecahkan masalah tersebut supaya dapat memecahkan masalah dengan efektif dan efisien.

\section{Calon Guru Matematika dan IPA yang Menguasai Teknologi}

Konten pendidikan seyogyanya disesuaikan dengan kebutuhan anak didik dan situasi kognitif dan psikososial serta nilai yang kita anut (NURFADHILAH, 2019). Konten dalam artian isi materi yang sesuai dengan kebutuhan siswa dan sesuai dengan kompetensi yang diminta dalam mata pelajaran tersebut. Nilai adalah penanman karakter yang harus dilakukan oleh guru baik guru matematika dan IPA dalam setiap pembelajarannya, kegiatan pendahuluan sampai dengan kegiatan penutup merupakan serangkaian kegiatan yang bisa dijadikan oleh guru untuk menysipkan nilai nilai yang menjadi ciri khas bangsa Indonesia.

Pendidikan 4.0 merupakan pendidikan yang bercirikan pemanfaatan teknologi digital dalam proses pembelajaran atau dikenal dengan sistem siber (cyber system) (Agus Supandi et al., 2019) (Wening, 2015). Tidak bisa dihindarkan lagi bahwa teknologi sudah menjadi kebutuhan. Penguasaan teknologi menjadi mutlak adanya bagi calon guru MIPA yang akan menjadi pengajar yang rata-rata siswanya sudah memahami dan menggunakan gadget dalam kesehariannya. Perlu kesdaran dari guru MIPA agar penggunaan gadget tersebut menjadi positif.

Pembuatan media interaktif bisa menjadi kunci agar siswa bisa belajar tanpa mengenal batas waktu dan jarak serta dapat diulang ulang sesuai dengan kebutuhan siswa tersebut. Media interaktif bisa menjadi jembatan agar materi yang disajikan dapat dipahami dengan baik oleh siswa. Uraian uraian tersebut mengharuskan calon guru MIPA memiliki ide yang kreatif untuk menglahirkan inovasi dalam pembelajaran yang membuat siswa menjadi lebih termotivasi dalam pembelajaran.

\section{KESIMPULAN}

Melalui kajian ini dapat disimpulkan bahwa 3 hal yang harus dipersiapkan agar calon guru MIPA bisa bersaing di Era Industri 4.0 adalah guru yang memiliki karakter, guru yang mampu menciptakan lingkungan pembelajaran yang kaya serta 
guru yang mampu dan cakap terhadap penguasan teknologi.

\section{DAFTAR PUSTAKA}

Abi, A. R. (2017). Paradigma Membangun Generasi Emas Indonesia Tahun 2045. Jurnal Ilmiah Pendidikan Pancasila Dan Kewarganegaraan, 2(2), 85-90. https://doi.org/10.17977/um019v2i22 $017 \mathrm{p} 085$

Agus Supandi, Sara Sahrazad, Arief Nugroho Wibowo, \& Sigit Widiyarto. (2019). Analisis Kompetensi Guru: Pembelajaran Revolusi Industri 4.0. Seminar Nasional Bahasa Dan Sastra Indonesia (Prosiding SAMASTA), 16.

Amini, A., Abdurrahman, A., Syaharuddin, S., Rizky Eka Tuningsih, J., \& Agustina, J. (2020). Goes to School: Sebuah Kegiatan Menginspirasi Siswa Menuju Generasi Emas Indonesia. JPMB : Jurnal Pemberdayaan Masyarakat Berkarakter, 3(1), 10-16. https://doi.org/10.36765/jpmb.v3i1.99

Arifian, F. D. (2019). Peran lembaga pencetak tenaga kependidikan (LPTK) dalam mempersiapkan generasi emas bangsa. Jurnal Pendidikan Dan Kebudayaan Missio, 11(1), 26-38.

Darman, R. A. (2017). Mempersiapkan Generasi Emas Indonesia Tahun 2045 Melalui Pendidikan Berkualitas. Jurnal Edik Informatika, 2(2), 73-83.

Ferryka, P. Z. (2013). Program 5 S ( Senyum, Sapa, Salam, Sopan, Santun ) Dalam Membangun Karakter Siswa Sekolah Dasar Untuk Menyongsong Generasi Emas. Journal of Chemical Information and Modeling, 53(9), 1689-1699.

Hendayani, M. (2019). Problematika Pengembangan Karakter Peserta Didik di Era 4.0. Jurnal Penelitian Pendidikan Islam, 7(2), 183. https://doi.org/10.36667/jppi.v7i2.368

Karima, M. K., \& Ramadhani. (2017). Peran Pendidikan Dalam Mewujudkan Generasi Emas Indonesia Yang Bermartabat. Jurnal Program Studi Pendidikan Ilmu Pengetahuan Sosial, 1(1), 1-21.

Khairat, A. (2016). Proceeding International Seminar on Education 2016 Faculty of Tarbiyah and Teacher Training. Proceeding International Seminar on Education 2016, 61-68.

Mahanal, S. (2014). Peran Guru dalam Melahirkan Generasi Emas dengan Keterampilan Abad 21. Seminar Nasional Pendidikan HMPS Pendidikan Biologi FKIP Universitas Halu Oleo, 20(September), 1-16.

NURFADHILAH, N. (2019). Analisis Pendidikan Karakter Dalam Mempersiapkan Pubertas Menuju Generasi Emas Indonesia 2045. Jurnal Pendidikan Dasar, 10(1), 85100.

http://journal.unj.ac.id/unj/index.php/j $\mathrm{pd} /$ article/view/11124

Rahim, F. R., Suherman, D. S., \& Murtiani, M. (2019). Analisis Kompetensi Guru dalam Mempersiapkan Media Pembelajaran Berbasis Teknologi Informasi Era Revolusi Industri 4.0. Jurnal Eksakta Pendidikan (Jep), 3(2), 133. https://doi.org/10.24036/jep/vol3iss $2 / 367$

Rohmadi, M. (2016). Pengembangan Profesionlisme Guru Indonesia untuk Menghasilkan Generasi Emas yang Profesional dan Berwibawa di Era MEA. Prosiding Seminar Nasional Inovasi Pendidikan Inovasi Pembelajaran Berbasis Karakter Dalam Menghadapi Masyarakat Ekonomi ASEAN, 1, 566-571.

Subekt, H., Taufiq, M., Susilo, H., Ibrohim, I., \& Suwono, H. (2017). Mengembangkan Literasi Informasi Melalui Belajar Berbasis Kehidupan 
Terintegrasi Stem Untuk Menyiapkan Calon Guru Sains Dalam Menghadapi Era Revolusi Industri 4.0: Revieu Literatur. Education and Human Development Journal, 3(1), 81-90. https://doi.org/10.33086/ehdj.v3i1.90

Sudrajat, A. (2011). Mengapa Pendidikan Karakter. Jurnal Pendidikan Karakter, I(1), 47-58. https://doi.org/10.21831/jpk.v1i1.131 6

Surani, D. (2019). Studi Literatur: Peran Teknolog Pendidikan Dalam Pendidikan 4.0. Prosiding Seminar Nasional Pendidikan FKIP, 2(1), 456-469.

Susongko, P., Hidayati, F., \& Isnani. (2020). Jurnal Pendidikan MIPA Pancasakti. E-Journal Ups, 4(januari 2020), 1-11.

Wati, I., \& Kamila, I. (2019). Pentingnya Guru Professional dalam Mendidik Siswa Milenial Untuk Menghadapi
Revolusi 4.0. Prosiding Seminar Nasional Pendidikan Program Pascasarjana Universitas PGRI Palembang, 12(1), 364-370. e-mail: missindah49@gmail.com

Wening, S. (2015). Inovasi Pendidikan Vokasi Bidang Busana Dalam Mempersiapkan Lulusan Calon Guru Berwawasan Global. Prosiding Pendidikan Teknik Boga Busana. https://journal.uny.ac.id/index.php/ptb b/article/view/30641

Yuliati, Y., \& Saputra, D. S. (2019). Pembelajaran Sains Di Era Revolusi Industri 4.0. Jurnal Cakrawala Pendas, 5(2), 167-171. https://doi.org/10.31949/jcp.v5i2.138 9 